\title{
Has the prevalence of stunting in South African children changed in 40 years? A systematic review
}

\author{
Rihlat Said-Mohamed*', Lisa K Micklesfield, John M Pettifor and Shane A Norris
}

\begin{abstract}
Background: In the last 20 years, South Africa has experienced political, economic, and demographic transitions accompanied by an epidemiological transition. Like several sub-Saharan countries, the South African population is facing both under-and over-nutrition, and nutrition and lifestyle related chronic disease while the burden of infectious disease remains high. It is critical to understand these trends overtime in order to highlights the pitfalls and successful measures initiatives taken in the efforts to tackle malnutrition. The objective of this systematic review is to investigate the changes in the prevalence of stunting, a chronic form of undernutrition, in South Africa over 40 years, and to derive lessons from the South African experience, a country in an advanced process of transition in sub-Saharan Africa.

Methods: We undertook a systematic review of publications selected from PubMed, Science Direct and Scopus. We included studies and surveys published between 1970 and 2013 if they reported the prevalence of stunting (low height-for-age) in children under-6 years of age living in South Africa. We excluded studies conducted in health facility outpatients or hospital wards, or children with known chronic and acute infectious diseases. We extracted Date of data collection, study setting, ethnicity, age, sex, sample size, growth references/standards, diagnostic criteria for stunting and prevalence of stunting from each study.
\end{abstract}

Results: Over the last decade, the national prevalence of stunting has decreased. However, between and within provincial, age and ethnic group disparities remain. Unlike other countries in sub-Saharan Africa, no sex or rural/urban differences were found in preschool children. However, the analysis of long-term trends and identification of vulnerable groups is complicated by the use of different growth references/standards and sampling methods.

Conclusion: Despite economic growth, political and social transitions, and national nutritional programs, stunting remains stubbornly persistent and prevalent in South Africa. A multi-sectoral and public health approach is needed to: (i) better monitor stunting over time, (ii) combat malnutrition during the first thousand days of life through continued efforts to improve maternal nutrition during pregnancy and infant feeding practices.

Keywords: Stunting, Undernutrition, Prevalence trends, Preschool children, South Africa, Sub-Saharan Africa

\section{Background}

In 2000, the United Nations Millennium Declaration committed 189 countries to halve the prevalence of underweight (weight-for-age $<-2 \mathrm{SD}$ of the median of the reference population) in children under-five years old [1]. Although underweight has been reduced by $26 \%$ between 1990 and 2011 in Sub-Saharan Africa (SSA), the progress

\footnotetext{
* Correspondence: Rihlat.SaidMohamed@wits.ac.za

MRC/Wits Developmental Pathways for Health Research Unit, Department of Paediatrics, Faculty of Health Sciences, University of the Witwatersrand, 7 York Rd, Parktown 2193, Johannesburg, South Africa
}

towards meeting the Millennium Development Goal 1 (MDG1) target has been limited since differences remain between rural and urban areas ( $43 \%$ vs. $30 \%$ ), low-and high-income households ( $48 \%$ vs. $25 \%$ ), and females and males (36 \% vs $42 \%$ ) [2].

Underweight does not distinguish between two different forms of malnutrition: (1) linear growth delay (stunting) due to chronic poor health and undernutrition; and (2) wasting associated with acute nutrient deprivation [3-6]. In 2008, the UN Standing Committee on Nutrition recommended that: "progress towards the achievement of

\section{Biomed Central}


MDG1 should be reported against reductions in the prevalence of stunting [...], not just underweight" [7]. In SSA, in 2011, $21 \%$ of children under-five years old were underweight versus $40 \%$ stunted $[2,8]$. Stunting is defined as having a height-for-age index more than two standard deviations below the World Health Organization Child Growth Standard median [2, 9]. Determinants of stunting are multi-factorial and mainly associated with households' low socio-economic status and food insecurity, repeated infectious episodes in infants and maternal health before, during and after pregnancy $[2,10]$. Stunting presents a significant public health concern due to increased morbidity and mortality during the life course. Being stunted has been associated with delayed cognitive development, impaired physical growth, lower productivity, and a greater risk of poor health including the development of cardiometabolic disease that may be transmitted to the next generation [11]. These short and long-term adverse effects on health and economics at individual, household and community levels highlight the need for reducing the prevalence of stunting [10]. In 2012 the WHO set Global Targets for Maternal, Infant and young Child Nutrition [12], the first of which is to reduce the number of stunted children under- 5 years of age by 2025 by $40 \%$.

In comparison to other countries of SSA, South Africa differs by: its long history of recording nutrition data through studies and national surveys, and its advanced stage of nutrition transition associated with political, economic and demographic transitions [13]. These last 20 years, South Africa has experienced rapid nutrition and lifestyle transitions associated with increased prevalence of obesity and non communicable disease as experienced by western countries [13]. However, the South African pattern of transitions differs in that stunting persists and, in addition to other factors, may fuel the epidemiologic trends of the degenerative disease aforementioned. As a result, understanding the long term dynamic of stunting in South Africa is required in order to efficiently orientate public health interventions and reduce the consequences of stunting on population health and economic development.

The main objective of this systematic review is to understand the trends in the prevalence of stunting between 1970, when the first articles [14, 15] reporting the prevalence of low height in children were published; and 2013, when the results of the last national nutritional survey [16] were published which is 2 years before the date for achieving the Millennium Development Goals [1]. In particular, this systematic review aims to: (1) provide an overview of the changes in the prevalence of stunting in South Africa in children under-six years old since 1970; (2) identify the vulnerable populations and locations; and (3) derive lessons from the South African experience.

\section{Methods}

The PRISMA Statement [17], evidence-based guidelines that provide a set of items to report in systematic reviews and meta-analyses, was used (Additional file 1).

\section{Eligibility}

Studies published between 1970 and August 2013, irrespective of language, that report the prevalence of stunting or a low height-for-age in children under-six years old in South Africa, irrespective of the growth curves and the cut-off points used, were included. Studies conducted in clinical outpatients or wards of health facilities, or on children with chronic or acute diseases (e.g., HIV, tuberculosis) were excluded due to representativeness limitations.

\section{Identification of studies}

Combinations of the following search terms were used in PubMed, Science Direct and Scopus: Stunting/-ed, Growth retardation, Height, Undernutrition, Malnutrition, South Africa, Humans, Under-five, Preschool, and Infant.

\section{Study selection}

Firstly, we used titles and abstracts to select the studies. When the abstracts were not available, we kept the studies for the next level of screening. Secondly, articles were read entirely. We included the studies that matched our inclusion criteria. When we excluded a study, reasons were recorded. When we identified studies that might have been appropriate while reading, the studies were searched for. When several studies used the same data, we included the most recent publication. For longitudinal studies that reported the prevalence of stunting in their cohort at different ages in different articles, we included the publication that reported the prevalence at 2-3 years of age, as in many low and middle-income countries growth faltering occurs during the first 2 years of life [18].

\section{Data extraction}

The following information were recorded in a database: date of data collection, study settings and designs, ethnicity, age, sex, sample size, reference/standard used to determine cut-off points, actual cut-off points for stunting, and the prevalence of stunting. Supplementary information were also recorded (e.g., objective of studies).

\section{Quality assessment}

To our knowledge, tools for the quality assessment of prevalence studies on malnutrition do not exist [19]. Therefore, the tool developed for studies on the prevalence of temporomandibular disorders [20] was used here because it allows for the calculation of a Total Quality Score (TQS). This was obtained for each study by summing the points assigned for each of the items included in 
the following sections: sampling; measurement; analysis. The TQS range was from 0 (very bad) to 20 (outstanding) points.

As essential criteria in the assessment of stunting in children are the accuracy of the measurement of height and age, the items in the measurement section had to be adapted as follows:

- Reliability was assessed by the adequacy of the method used to measure height, and scored: 0 , if the equipment used was not described; 1 , if it was described and 2, if it was described, calibrated, and an inter-reliability coefficient was provided;

- Validity was assessed by the accuracy of the respondents' age recorded and scored: 0 , if the source of the child's age was not provided; 1 , if the age was provided by schools/parents, and 2, if the age was recorded from Road-to-Health card/clinical records/birth certificate.

\section{Data analyses}

Publications were heterogeneous in terms of:

i. Growth references/standards. From 1970 to 2013, a variety of growth references/standards were used, namely Harvard [21], NCHS [22], CDC [23] and the WHO [9]. Since they were developed based on different population and selection criteria; it is inappropriate to compare the prevalence of stunting between studies using different growth references/ standards. Thus the differences in prevalence of stunting between various studies were only compared if the same growth reference was used.

ii. Definition of stunting. Stunting was defined variably (height-for-age $<80 \%$ or $<90 \%$ of the median, or $<3^{\text {rd }}$ or $<5^{\text {th }}$ percentiles, or -2 SD from median of the reference population). Since the reference values for height-for-age follow a Gaussian curve, cut-off points defined as percentiles and z-scores are very close to each other $[24,25]$ allowing comparisons.

iii. Representativeness. Data were separated according to the region covered, namely national, provincial, urban or rural area.

iv. Ethnic groups. Ethnic groups are used as reported in the articles and are consistent with the South African census terms [26]: black (African), coloured (mixed ancestry), white (European) and Indians (Asians from the subcontinent).

v. Age and sex. Where studies reported the prevalence for different age ranges or sex, the prevalence for the whole sample (both sexes or all ages) was calculated provided the sample size for each subgroup was given. vi. Year. Prevalence were dated according to the year of data collection, when provided, otherwise the year of publication was used.

A Z-test was used to compare the prevalence of stunting between time points where appropriate (e.g., between surveys using the same reference/standard).

\section{Results}

Eight thousand one hundred twenty three references were identified using the defined electronic databases (Fig. 1). Among them, 124 references whose titles or abstracts mentioned our search terms or reported the prevalence (or percentage) of at least one of the forms of malnutrition (undernutrition, wasting, underweight) were selected and read entirely. Of the 124 references, 21 could not be procured (Additional file 2) despite searches (internet, University of the Witwatersrand libraries, contact with The South African Nutrition Society). Publications were excluded because: the prevalence of stunting was not reported $(n=13)$, the age range was $>6$ years of age $(n=18)$, data published elsewhere were used $(n=14)$, the reference was a review $(n=1)$, or there was potentially biased recruitment $(n=7)$. Fifty studies were included in the systematic review (Additional file 3).

\section{Description of publications (Additional file 2)}

Nine national surveys [16, 27-34], 39 cross-sectional $[14,15,35-71]$ and one longitudinal [72, 73] studies were reviewed. Eight used the Harvard references, 31 used NCHS references, and four used the WHO standards. One study compared NCHS, CDC and WHO references, and one study compared NHANES I and II references. For five articles, the growth reference/standard used could not be discerned [43, 57-60].

We found three studies of poor quality (TQS $\leq 4), 13$ of moderate quality $(5 \leq \mathrm{TQS} \leq 9), 12$ of good quality $(10 \leq \mathrm{TQS} \leq 14)$ and 16 of outstanding quality (TQS $\geq 15)$. The aims of studies were: assessment of children's nutritional status $[14,15,36,40,41,43,45,50-54,57,60,66$, 68-73], study of children's growth patterns [37, 38, 43, 63, $71,73]$, baseline of intervention studies or programs [14, $39,42,44,46,48,50,53,55,56,59-62,65,67,69]$, assessment of the relationship between ecological factors and children's health status $[15,35,36,41,47-49,62,67,68,70,72]$.

\section{Evolution of the number of publications}

The first publications documented dates from the mid1970's [14, 15] (Fig. 2). The period from 1980 to 1999 is characterized by a progressive increase in the number of regional studies while the number of national surveys slowly increased from 1990 to 2010. 


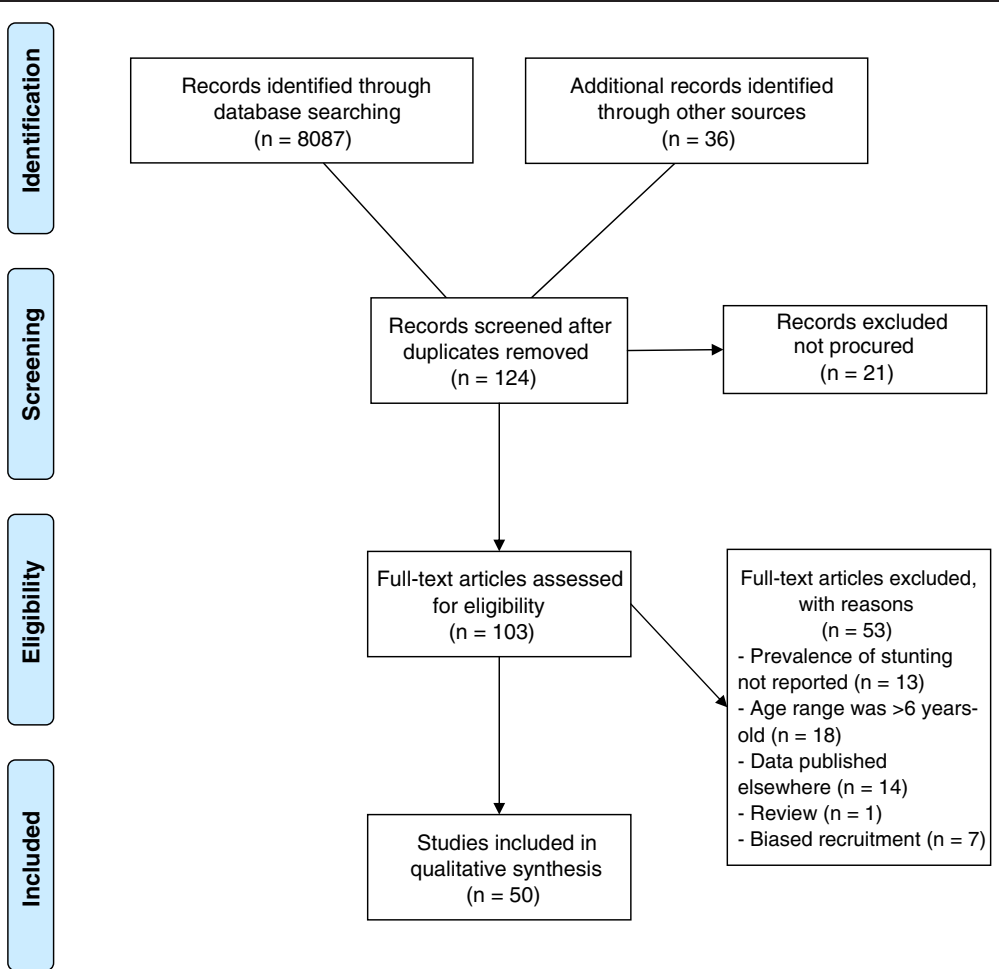

Fig. 1 Flow Diagram

\section{Trends}

The national prevalence of stunting is illustrated in Fig. 3. Using the NCHS reference, from 1993 [30] to 2003 [32] the prevalence of stunting increased by $2.9 \%$ (z-test, p < $0.05)$. Using the WHO standard, the prevalence of stunting decreased by $5.9 \%$ between 1999 [34] and 2013 [16] (z-test, p < 0.001). However, the 2008 National Income Dynamic Study (NIDS) showed an increase of $6.8 \%$ from the 2005 National Food Consumption Survey (z-test, p < 0.001). A significant difference in the prevalence of stunting was found on data from the 1999 National Food Consumption Survey using the NCHS [31] and WHO
[34] references/standards (21.9\% vs. $25.4 \%$; z-test, p < 0.05). This comparison illustrates the concerns around the use of different growth references [73]. In 2013 [16], the prevalence of stunting was higher in $0-3$ years old than in their 4-6 year old peers ( $\mathrm{z}$-test, $\mathrm{p}<0.001$ within both sexes). The prevalence was similar between sexes at each time point.

Figure 4 shows the prevalence of stunting in each province from the three national surveys that published provincial data in the 1993 Living Standards and Development Survey [30]; the 1994 South African Vitamin A Consultative Group (SAVACG) [29]; and the 2003 Demographic Health

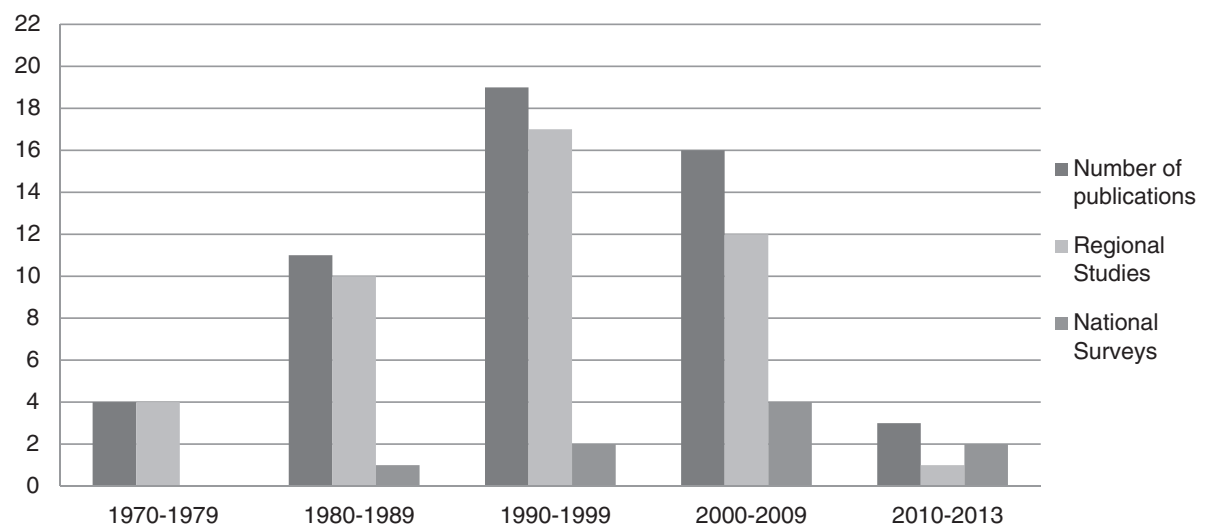

Fig. 2 Total number of publications, number of regional studies and number of national surveys included in the systematic review, per decade 


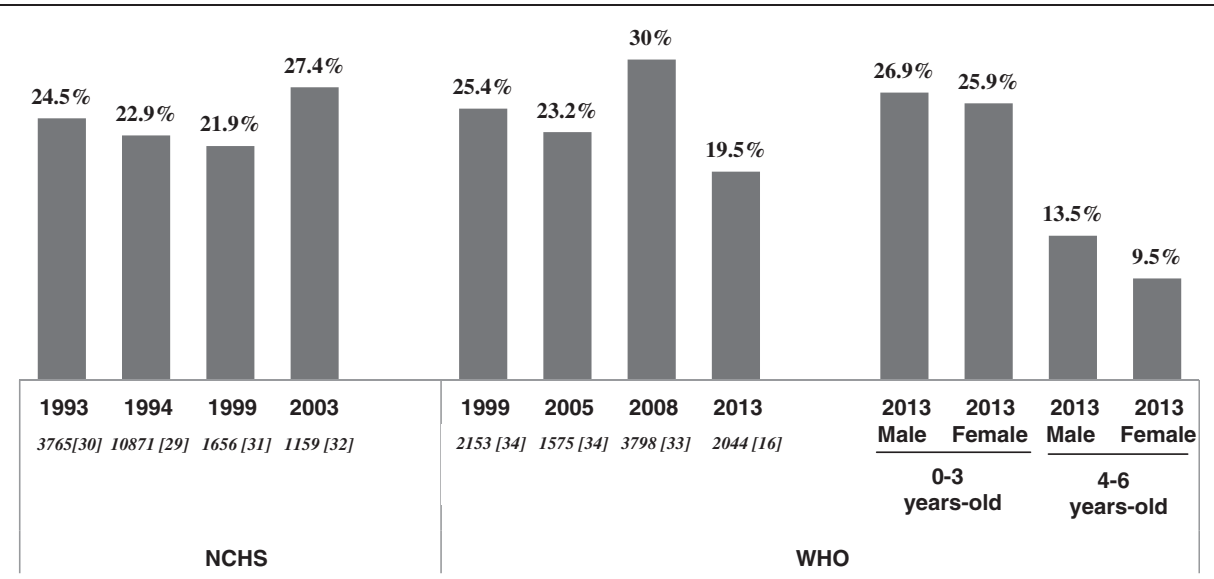

Fig. 3 National prevalence of stunting in South Africa 1993-2013. Living Standards and Development Survey (1993) [30]; SA Vitamin A Consultative Group (1994) [29]; National Food Consumption Survey (1999) [31, 34]; Demographic and Health Survey (2003) [32]; National Income Dynamic Survey (2008) [33]; National Food Consumption Survey (2005) [34]; South Africa first National Health And Nutrition Examination Survey (2013) [16]. Sample size in italics [reference number], sample size of male and female 0-3 years-old $=537$ and 553, respectively; sample size of male and female 4-6 years-old $=503$ and 451, respectively

Survey (DHS) [32]. Qualitatively, the figure shows that the majority of rural provinces, Eastern Cape (EC), Northwest province and Mpumalanga, have a high but consistent level of stunting in comparison to Gauteng (GP) and Western Cape (WC) that show marked fluctuations. The sample sizes per province were not provided for the 1993 national survey [30]. As a result, it is impossible to assess whether the large differences in prevalence observed between 1993 and 1994, in particular in GP (from $18 \%$ to $12 \%$ ), in KwaZulu-Natal (KZN, from $25 \%$ to $16 \%$ ), in WC (from $17 \%$ to $12 \%$ ) and Limpopo (from $27 \%$ to $34 \%$ ), are statistically significant. Between 1994 [29] and 2003 [32], there were significant increases in the prevalence of stunting from $23 \%$ to $37 \%$ in Northern Cape $(\mathrm{NC})(\mathrm{p}<0.05)$, from $12 \%$ to $35 \%$ in WC ( $<<$
$0.001)$ and from $12 \%$ to $27 \%$ in GP $(\mathrm{p}<0.001)$. In the DHS [32], small sample sizes at provincial level may impact on the representativeness of the estimates and suggests a cautious interpretation. In 1994, the prevalence of stunting found by the SAVACG [29] in KZN were significantly higher than those reported in the Department of Health Primary Schools Survey in the same year [28] (z-test, $\mathrm{p}<0.001$ and $\mathrm{p}<0.001$, for boys and girls respectively). The discrepancy could be due to age range differences between the two surveys (SAVACG [29] on 0-5 year-old children, primary schools survey [28] on 4-5 year-old children) as stunting is most prevalent in the first two years of life. In addition, samples may differ between these two studies since the primary school survey did not include primary school age children that did not attend

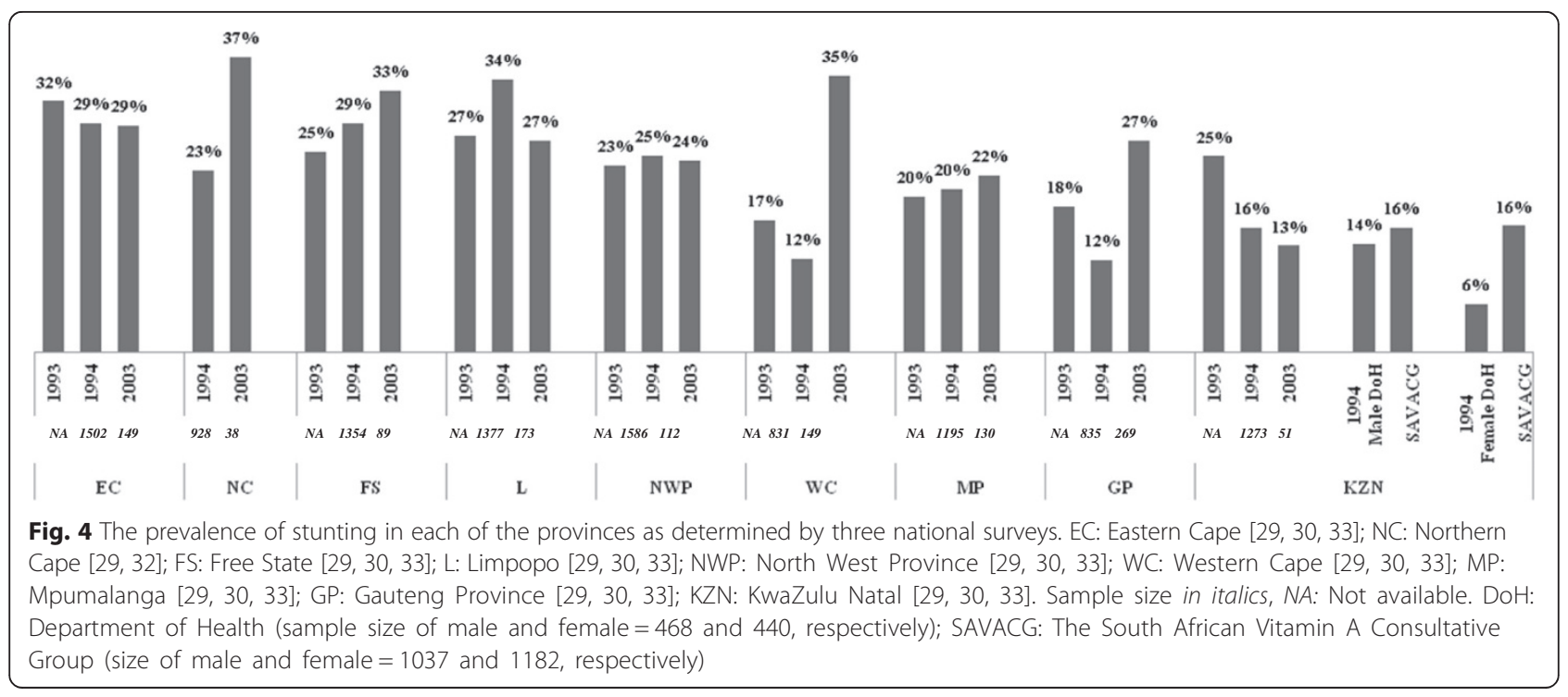


school. In 2003, the provinces with the highest prevalence of stunting were NC, Free State (FS), and WC [32].

Only two of the three national surveys [32, 33], that published ethnicity data, reported the prevalence of stunting in Indians, which is likely to have large confidence intervals considering the limited sample sizes (Additional file 4). The sample sizes were not provided for the 1993 survey [30], therefore it is difficult to assess whether there is statistical differences in the prevalence of stunting in the different ethnic groups between 1993 and 2003. Data from the NIDS [33], reported a higher prevalence of stunting in black and mixed ancestry children than white and Indian children (z-test, $\mathrm{p}<0.001$ for all comparisons).

At a national level, the prevalence of stunting increased by $10 \%$ between 1994 [29] and 2003 [32] (z-test, $\mathrm{p}<0.001$ ) in urban black children, and by $3 \%$ between 1986 [27] and 2003 [32] in rural black children (z-test, $\mathrm{p}<0.01$ ) (Additional files 5 and 6). In 2003 [32], there was no statistical difference in the national prevalence of stunting between urban $(26.9 \%)$ and rural areas $(28 \%)$. The figures show that the prevalence of stunting is not documented for all provinces or for all ethnic groups (black Africans are represented in $80 \%$ of the studies) over time, and that there are disparities between localities within provinces. For studies that used the NCHS standard, the prevalence of stunting reported in the ad hoc studies in rural or urban areas, are in line or slightly higher for particular groups than in the national surveys done around the same year/period (Additional files 5 and 6). However, there were wide ranges reported which suggests that there are pockets or areas where stunting is a greater burden than other areas.

\section{Discussion}

\section{Temporal changes in the number of studies on stunting} in children

In South Africa, between 1960 and 1990, there was a reduction in the importance of undernutrition as a government public health concern [74]. Indeed, the Department of Nutrition (under the Ministry of Health) was disbanded and the activities of the National Nutrition Council, whose mandate was to conduct research in nutrition, slowly declined [74]. However, the increase of publications on stunting during that 30 years period shows that in the meantime stunting was a growing health concern among the academics. At the international level, until 1970, underweight was the main indicator of malnutrition which contributes to explain that there were fewer studies conducted on stunting in children. It is in 1971 that the Joint FAO/WHO meeting [75] emphasized the importance of assessing height in relation to age [24, 76, 77]. In addition, from the 1970s, nutritional epidemiology experienced major changes that improved the evaluation of nutritional status, including the standardization of methods, the homogenization of the indicators and the definition of their cut-off points $[24,25,78]$, the creation of the first international growth curves (NCHS) [22], and the use of advanced technology and tools for data analyses. In 1995, the creation of a Directorate of Nutrition (under the Department of Health) and the launch of the Integrated Nutrition Program in 1996 was a sign of the recognition of malnutrition as a national public health concern in South Africa.

In this systematic review we found that the number of publications on stunting reached a peak in the 1990s. Although, the number of publications diminished in the 2000 s, six national surveys [16, 30-34] were published providing a regular assessment of the prevalence of stunting. In addition, regional studies have provided supplementary information on malnutrition and the associated ecological factors in high risk areas [62, 65, 67-70].

\section{Temporal trends in the prevalence of stunting}

Our review highlights methodological challenges when trying to understand temporal trends in stunting prevalence. Firstly, differences between growth standards/references only allow for comparisons between prevalence estimates using the same standard/reference, as the prevalence changes according to the growth standard/references used. As reported in other countries [79], the use of the WHO standard has been shown to increase the prevalence of stunting in the South African population [31, 34, 73]. In addition, the cut-off points used to define stunting have varied within these references/standards, which increase the degree of variability of the prevalence estimates. Secondly, we observed fluctuations in the prevalence of stunting across time that may be a result of different sampling methodologies. The increase in the national prevalence of stunting by $6.5 \%$ over a 3-year period (between 2005 and 2008) may be real but differences in sampling methods, that do not capture comparable socio-demographic variability, may also be responsible for some of the difference. Sampling concerns are exacerbated in longitudinal/crosssectional studies that often target vulnerable populations and as a consequence are not representative of the provinces where the studies were undertaken.

This review also underlines the persistence of stunting and its heterogeneous distribution across the age ranges. Our analysis suggests that the national prevalence compared to the 1993 figure [30] had increased by 3 to $5 \%$ by 2008 [33], but had decreased by $10.5 \%$ by 2013 [30]. Both the NIDS in 2008 and the SANHANES in 2013 used rigorous sampling methodologies [16, 80]. Therefore the large decrease in stunting between these surveys may suggest: (i) trickling down of economic growth that has improved maternal and child nutrition; and (ii) successful reduction in mother-child transmission of HIV. However, the most recent stunting prevalence data of 
$26.9 \%$ in boys and $25.9 \%$ in girls between 0 and 3 years of age, confirms that stunting persists as a public health burden [16]. Impaired growth during early life has been associated with delays in cognitive development, and an increased risk of obesity and cardio-metabolic disease later in life $[11,81]$. The short and long-term adverse effects highlight the importance of tackling stunting early in life to improve human capital globally [11]. The first thousand days of life, from conception to 2 years of age, have been identified as a window of opportunity for interventions to improve childhood growth and development, and reduce future disease risks [82, 83].

\section{Regional changes in the prevalence of stunting}

Our analysis shows that the burden of stunting is not homogeneous across provinces. Between 1994 [30] and 2003 [16], large increases in the prevalence of stunting were noted in the NC, WC and GP. In addition to sampling differences over time, the migration pattern during that period could partly explain that observation. In the 1990's, labour populations, predominantly from the homelands, migrated to the provincial metropolises of GP and WC where they established informal settlements $[84,85]$. Little is known about the pattern of preschool children's mobility but it could be motivated either by maternal migration or the families searching for better access to child care $[86,87]$. The transition from rural homes to the generally poor living conditions in urban shacks may contribute to poor health outcomes in children [86].

Over the last two decades prevalence rates of stunting $\geq 20 \%$ were reported in the EC, NC, FS, North West province, and Limpopo. These mainly rural provinces have had fewer studies, probably reflecting the lack of resources such as funding opportunities, medical/public health academies and facilities [88]. In addition, these provinces have higher percentages of unemployment and poverty, and informal settlements [89] with poor access to water and sanitation. In South Africa, the National Department of Health is responsible for national health policy and each province is in charge of developing its own implementation of the national policy [90]. Given the provincial differences, cooperation between the provincial health administrations should be encouraged to highlight policies and programs that work.

Stunting is highly correlated with poorer socio-economic status and environmental conditions [30] and despite the efforts to enhance equity since the introduction of democracy in 1994, South Africa still has one of the highest income inequalities with black and mixed ancestry groups being the most impoverished [90]. Surveys show a higher prevalence of stunting in black and mixed ancestry South African children compared to their white and Indian peers. Unlike the findings from other Sub-Saharan African countries [2, 91], no rural-urban [32] or sex [16, 32] differences were found in the prevalence of stunting in under- 6 year old children. In fact, urbanization leads to an increase number of inhabitants in informal settlements and, as a consequence, to a rise of poor health outcomes in these areas $[16,92]$. Interestingly, when looking at a wider age range (0-14 years), recent surveys $[16,33]$ report that the highest prevalence of stunting is found in children living in informal settlements of rural and urban areas. Accordingly, differences could exist in the prevalence of stunting in children under- 6 years of age within both rural and urban settings in communities with different socio-economic status which is in line with the disparities within provinces which have been observed over time. However, it could not be assessed in this review as these prevalence rates are not provided by recent surveys.

\section{Conclusions}

South Africa is far from reaching the MDG1 [93, 94]. This systematic review indicates that despite economic transition over the past 40 years, stunting still persists at a significant level. This observation suggests that the implementation of the national strategy (the Integrated Nutrition Programme) in 1996 has not reduced the prevalence of early life malnutrition. In that regards, the 2009 Landscape Analysis [95] helped to identify critical restraints and to make nutrition-related recommendations to scale-up the national nutrition programs. For instance, the Directorate of Nutrition (National Department of Health) defined a Roadmap for Nutrition in South Africa for the period of 2013 - 2017 [96] which advocates for a multi-sectoral approach to tackle malnutrition including a lifecycle approach focusing on the key 'window of opportunity', from pregnancy to two years of age (the first 1000 days). Other low and middle income countries in rapid transition, such as Brazil and India, have adopted a multi-sectoral approach. This approach is characterized by the implementation of interventions against malnutrition that are equity driven, nutrition sensitive and specific to the targeted populations. This multi-sectoral approach has resulted in a significant decrease in the prevalence of stunting. The success of the approach is also due to anchoring interventions into programs of different institutional sectors that are directly or indirectly linked to the issue of malnutrition (e.g., agricultural policies). In Brazil stunting prevalence of children under 5 years of age has decreased from $37.4 \%$ in 1974 to $7.1 \%$ in 2007 , and has been attributed to strong political commitments and to improvements in (1) the purchasing power of low-income families; (2) female education levels; (3) public water and sanitation systems; (4) access to basic health care, and (5) the quantity and quality of subsistence crops $[9,97]$. In India, the Rajmata Jijau Mother-Child Health and Nutrition Mission [9], which was aimed at promoting behavioral changes, advocating to policy makers for the importance of the first 1000 days; 
promoting the active participation of the community; and, measuring the impact of the programmes succeeded in halving the prevalence of stunting in children under 2 years of age between 2005 and 2012.

This systematic review recognizes the difficulty in comparing surveys over time, and recommends that South African public health practitioners and policy-makers to: (1) adopt one growth standard for the assessment of stunting; (2) agree on the sampling methodology for national surveys; (3) generate representative data at provincial levels to improve the national sampling framework; and (4) lodge and archive national survey datasets with the Department of Health (or the South African Medical Research Council) such that these data can be reanalyzed if necessary in the future. Addressing these issues would facilitate better monitoring of malnutrition, identify vulnerable communities and individuals, and improve national policies and local programs [8].

The experience of South Africa, the most developed economy in sub-Saharan Africa, highlights the difficulties in tackling malnutrition on the sub-continent. The persistence of early life malnutrition is fueling the burden of non-communicable disease, an emerging public health concern in Sub-Saharan Africa.

\section{Additional files}

\section{Additional file 1: PRISMA 2009 Checklist. \\ Additional file 2: List of the references that could not be procured. \\ Additional file 3: List of the references included in the systematic review.}

Additional file 4: Evolution of national prevalence of stunting by ethnic groups. Histogram of ethnic prevalence of stunting in children less than 6 years of age.

Additional file 5: Prevalence of stunting in urban areas per provinces. Histogram of regional prevalence of stunting in children less than 6 years of age.

Additional file 6: Changing prevalence of stunting in rural areas: national and black population prevalence. Histogram of regional prevalence of stunting in children less than 6 years of age.

\section{Abbreviations \\ CDC: Centers for Disease Control and prevention; DHS: Demographic Health Survey; EC: Eastern Cape; FS: Free State; GP: Gauteng Province; KZN: KwaZulu Natal; MDG: Millennium Development Goal; NC: Northern Cape; \\ NCHS: National Center for Health Statistics; NHANES I and II: The National Health and Nutrition Examination Survey I and II; NIDS: The National Income Dynamic Study; PRISMA: Preferred Reporting Items for Systematic Reviews and Meta-Analyses; SANHANES-1: The first South African National Health And Nutrition Examination Survey; SAVACG: The South African Vitamin A Consultative Group; SSA: Sub-Saharan Africa; TQS: Total Quality Score; WHO: World Health Organization; WC: Western Cape.}

\section{Competing interests}

The authors declare that they have no competing interests.

\section{Authors' contributions}

RSM contributed to the conceptualization of the study, did the study selection, the data extraction, analysis and interpretation, drafted the initial manuscript, and approved the final manuscript as submitted. LKM and SAN contributed to the conceptualization of the study, the study selection, data analysis and interpretation, reviewed and revised the manuscript, and approved the final manuscript as submitted. JMP contributed to the conceptualization of the study, the data analysis and interpretation, reviewed and revised the manuscript, and approved the final manuscript as submitted. All authors read and approved the final manuscript as submitted and agree to be accountable for all aspects of the work.

\section{Authors' information}

RSM has a PhD in Biological Anthropology and is currently post-doctoral Research fellow. Her research interest is on biological, social and cultural determinants of linear growth and body composition in children. LKM has a PhD in Physiology and her research interests include body composition throughout the life course.

JMP is a paediatrician with a PhD and his research interests are infant and child nutrition and paediatric bone and mineral metabolism.

SAN has a PhD in Physiology with research expertise in child growth and development in Africa.

\section{Acknowledgements}

Funding source: the MRC/DFID African Research Leader Scheme is funding RSM's post-doctoral research fellowship.

Received: 28 January 2015 Accepted: 15 May 2015

Published online: 05 June 2015

\section{References}

1. United Nation. We can end poverty. Millennium Development goals and beyond 2015. www.un.org/millenniumgoals/. Accessed 03 December 2013

2. United Nations Children's Fund (UNICEF). Improving Child Nutrition. The achievable imperative for global progress. New York: Division of Communication, UNICEF; 2013. www.unicef.org/publications/index_ 68661.html. Accessed 03 October 2013.

3. Chabra R, Rokx C. The Nutrition MDG Indicator. Interpreting Progress. Washington DC: World Bank; 2004.

4. United Nations Children's Fund (UNICEF). Tracking Progress on Child and Maternal Nutrition. A Survival and Development Priority. New York: Division of Communication, UNICEF; 2009. p. 119. www.unicef.org/publications/ index_51656.html. Accessed 03 December 2013.

5. Fanzo JC, Pronyk PM. A review of Global progress toward the Millennium Development Goal 1 Hunger Target. Food Nutr Bull. 2011;32(2):144-58.

6. Klaver W. Underweight or Stunting as an Indicator of the MDG on Poverty and Hunger. Leiden: African Studies Center; 2010. ASC Working Paper 92 / 2010. 41 p. https://openaccess.leidenuniv.nl/handle/1887/16313. Accessed 03 December 2013

7. United Nation System Standing Committee on Nutrition. Accelerating the Reduction of Maternal and Child Undernutrition. Recommendations from the $35^{\text {th }}$ SCN Session. Hanoi: United Nation System Standing Committee on Nutrition; 2008. www.unscn.org/files/Statements/ 35th_Session_Recommendations.pdf. Accessed 03 December 2013.

8. Stevens GA, Finucane MM, Paciorek CJ, Flaxman SR, White RA, Donner AJ, et al. Nutrition Impact Model Study Group (Child Growth). Trends in mild, moderate, and severe stunting and underweight, and progress towards MDG 1 in 141 developing countries: a systematic analysis of population representative data. Lancet. 2012;380(9844):824-34.

9. World Health Organization (WHO). WHO Child Growth Standards: Methods and Development. Geneva: Department of Nutrition for Health and Development, World Health Organization; 2007.

10. World Health Organization (WHO). Global Nutrition targets 2025: Stunting Policy Brief (WHO/NMH/NHD/14.3). Geneva: World Health Organization; 2014.

11. Victora CG, Adair L, Fall C, Hallal PC, Martorell R, Richter L, et al. Maternal and child undernutrition: consequences for adult health and human capital. Lancet. 2008;371:340-57.

12. de Onis M, Dewey KG, Borghi E, Onyango AW, Blössner M, Daelmans B, et al. The World Health Organization's global target for reducing childhood stunting by 2025: rationale and proposed actions. Matern Child Nutr. 2013;9(S2):6-26.

13. Abrahams Z, McHiza Z, Steyn NP. Diet and mortality rates in Sub-Saharan Africa: stages in the nutrition transition. BMC Public Health. 2011;13(11):801. 
14. Margo G, Lipschitz S, Joseph E, Green R, Metz J. Protein calorie malnutrition and nutritional anaemia in Black pre-school children in a South African semirural community. S Afr Med J. 1976;50(3):67-74.

15. Margo G, Baroni $Y$, Brindley M, Green R, Metz J. Protein energy malnutrition in mixed ancestry children in Western Township, Johannesburg. Part II. Prevalence and severity. S Afr Med J. 1976;50(32):1241-5.

16. Shisana O, Labadarios D, Rehle T, Simbayi L, Zuma K, Dhansay A, et al. Faber $M$, and the SANHANES-1 Team South African National Health and Nutrition Examination Survey (SANHANES-1). Cape Town: HSRC Press; 2014.

17. Moher D, Liberati A, Tetzlaff J, Altman DG, The PRISMA Group. Group. Preferred Reporting Items for Systematic Reviews and Meta-Analyses: The PRISMA Statement. PLoS Med. 2009;6(6), e1000097.

18. Victora CG, de Onis M, Hallal PC, Blössner M, Shrimpton R. Worldwide timing of growth faltering: revisiting implications for interventions. Pediatrics. 2010;125(3):e473-80.

19. Shamliyan T, Kane RL, Dickinson S. A systematic review of tools used to assess the quality of observational studies that examine incidence or prevalence and risk factors for diseases. J Clin Epidemiol. 2010;63(10):1061-70.

20. Giannakopoulos NN, Rammelsberg P, Eberhard L, Schmitter M. A new instrument for assessing the quality of studies on prevalence. Clin Oral Investig. 2012;16(3):781-8.

21. Stuart HC, Stevenson SS. Physical growth and development. In: Nelson WE, editor. Textbook of Pediatrics. 7th ed. Philadelphia: Saunders; 1959. p. 12-61.

22. National Center for Health Statistics. NCHS Growth Curves for Children, Birth to 18 Years. Washington DC: Department of Health, Education, and Welfare, National Center for Health Statistics; 1977. DHEW publication No. 78-1650.

23. Kuczmarski RJ, Ogden CL, Guo SS, Grummer-Strawn LM, Flegal KM, Mei Z, et al. 2000 CDC growth charts for the United States: Methods and development. Hyattsville (Maryland): Department of health and human services, Centers for Disease Control and Prevention and National Center for Health Statistics; 2002. DHHS publication number (PHS) 2002-1696. Vital Health Statistics 11(246).

24. Waterlow JC, Buzina R, Keller W, Lane JM, Nichaman MZ, Tanner JM. The presentation and use of height and weight data for comparing the nutritional status of groups of children under the age of 10 years. Bull World Health Organ. 1977;55(4):489-98.

25. WHO expert committee. Physical Status: the use and Interpretation of Anthropometry. Geneva: World Health Organization; 1995. WHO Technical Report Series 854.

26. Statistics South Africa. Census 2011. Census in brief. Pretoria: Statistics South Africa; 2012. Report number: 03-01-41. http://www.statssa.gov.za/census/census_ 2011/census_products/Census_2011_Census_in_brief.pdf. Accessed 18 May 2015.

27. The Regional Health Organization for Southern Africa (RHOSA). First RHOSA nutrition study. Anthropometric assessment of nutritional status of black under fives in rural RSA. Epidem Comments. 1987;14:1-44.

28. Department of Health. Anthropometric Survey in Primary Schools in the Republic of South Africa (RSA): 1994. Pretoria: Department of Health; 1994.

29. The South African Vitamin A Consultative Group. Children aged 6 to 71 months in South Africa, 1994: their Anthropometric, Vitamin A, Iron and Immunisation Coverage Status. Johannesburg: The South African Vitamin A Consultative Group; 1995

30. Zere E, McIntyre D. Inequities in under-five child malnutrition in South Africa. Int J Equity Health. 2003;2(1):7.

31. Steyn NP, Labadarios D, Maunder E, Nel J, Lombard C. Directors of the National Food Consumption Survey. Secondary anthropometric data analysis of the National Food Consumption Survey in South Africa: the double burden. Nutrition. 2005:21(1):4-13.

32. Department of Health, Medical Research Council, OrcMacro. South Africa Demographic and Health survey 2003 (SADHS). Pretoria: Department of Health; 2007.

33. Ardington C, Case A. Health: Analysis of the National Income Dynamics Study (NIDS) wave 1 dataset. Cape Town: Southern Africa Labour and Development Research Unit, School of Economics, University of Cape Town; 2009. Discussion paper number 2/15

34. Kruger HS, Steyn NP, Swart EC, Maunder EM, Nel JH, Moeng L, et al. Overweight among children decreased, but obesity prevalence remained high among women in South Africa, 1999-2005. Public Health Nutr. 2012;15(4):594-9.

35. Shuenyane E, Mashigo S, Eyberg C, Richardson BD, Buchanan N, Pettifor J, et al. A socio-economic, health and cultural survey in Soweto. S Afr Med J. 1977:51(15):495-500.
36. Westcott GM, Stott RA. The extent and causes of malnutrition in children in the Tsolo district of Transkei. S Afr Med J. 1977:52(24):963-8.

37. Richardson BD. Malnutrition and nutritional anthropometry. J Trop Pediatr. 1980;26(3):80-4

38. Adhikari M, Coovadia H. Mid-upper arm circumference in the assessment of growth retardation. S Afr Med J. 1981;9(2):32.

39. Krynauw JD, Fincham RJ, Kotzé JP. An anthropometric survey of the nutritional status of black preschool children in the Dias Divisional Council area, May 1981. S Afr Med J. 1983;64(28):1095-8.

40. Ndlovu SM. An Assessment of the Nutritional Status of Infants and Children Under the Age of Five in Semi-Urban and Rural Areas of Kwazulu [dissertation]. Kwa Dlangezwa, South Africa: University of Zululand; 1984.

41. Lazarus T, Bhana K. Protein-energy malnutrition and associated variables among Indian pre-school children in a selected area of Natal. S Afr Med J. 1984;65(10):381-4

42. Richardson BD, Sinwel RE. Infant growth in a rural Tswana community. S Afr Med J. 1984:65(19):775-8.

43. Richardson BD. Changes in anthropometric measurements of South African children-a cause for concern. S Afr Med J. 1986;69(1):11-2.

44. Househam KC, Elliott E. Nutritional status of black children under 5 years old attending a municipal clinic in Bloemfontein. S Afr Med J. 1987;71(8):494

45. Hugo-Hamman CT, Kibel MA, Michie CA, Yach D. Nutrition status of pre-school children in a Cape Town township. S Afr Med J. 1987;72(5):353-5.

46. Jacobs M, Joubert $\mathrm{G}$, Hoffman M. Anthropometric assessment of children in Mamre. S Afr Med J. 1988;74(7):341-3.

47. Byarugaba J. The impact of urbanization on the health of black pre-school children in the Umtata district, Transkei, 1990. S Afr Med J. 1991;79(8):444-8.

48. le Roux IM, le Roux PJ. Survey of the health and nutrition status of a squatter community in Khayelitsha. S Afr Med J. 1991;79(8):500-3.

49. Ramphele MA, Heap M, Trollip DK. Health status of hostel dwellers. Part III. Nutritional status of children 0-5 years. S Afr Med J. 1991;79(12):705-9.

50. Barron PM, Ferrinho PD, Buch E, Gear JS, Morris A, Orkin FM, et al. Community health survey of Oukasie, 1987. S Afr Med J. 1991;79(1):32-4.

51. Steyn NP, Badenhorst CJ, Nel JH, Jooste PL. The nutritional status of Ped preschool children in two rural areas of Lebowa. S Afr J Food Sci Nutr. 1992;4(2):24-8.

52. Coetzee DJ, Ferrinho P. Nutritional status of children in Alexandra township. Clinic-based data and a community survey. S Afr Med J. 1994;84(7):413-5.

53. Solarsh GC, Sanders DM, Gibson CA, Gouws E. Community-based survey versus sentinel site sampling in determining the nutritional status of rural children. Implications for nutritional surveillance and the development of nutritional programmes. S Afr Med J. 1994;84(11):747-52.

54. Bourne LT, Langenhoven ML, Steyn $K$, Jooste PL, Laubscher JA, Bourne DE. Nutritional status of 3-6 year-old African children in the Cape Peninsula. East Afr Med J. 1994;71:695-702.

55. Steyn NP, Nel JH, Tichelaar HY, Prinsloo JF, Dhansay MA, Oelofse A, et al. Malnutrition in Pedi preschool children, their siblings and caretakers. South Afr J Clin Nutr. 1994;7:12-8

56. Coutsoudis A, Jinabhai CC, Coovadia HM, Mametja LD. Determining appropriate nutritional interventions for South African children living in informal urban settlements. S Afr Med J. 1994;84(9):597-600.

57. Grant JP. The State of the World's Children 1994. UK: Oxford University Press; 1994.

58. Wagstaff LA, Fleming AF, Mkhasibe C, Becker PJ, Macphail AP. Iron status in under five year old children in greater Johannesburg and Soweto. SA J Food Sci Nutr. 1994;6(1):13-6.

59. Walsh CM. The Effect of A Nutrition Education Programme on the Knowledge of Nutrition and Dietary Practices of Lower Socio-Economic Mixed Ancestry Communities [dissertation]. Bloemfontein: University of the Orange Free State; 1995.

60. Dannhauser A, Joubert G, Nel M. Nutritional status of preschool children in the Bloemfontein district. SA J Food Sci Nutr. 1996;8(1):14-22.

61. Oelofse A, Faber M, Benadé JG, Benadé AJ, Kenoyer DG. The nutritional status of a rural community in KwaZulu-Natal, South Africa: the Ndunakazi project. Cent Afr J Med. 1999;45(1):14-9.

62. Dannhauser A, Bester $C$, Joubert $G$, Badenhorst $P$, Slabber M, Badenhorst A et al. Nutritional status of preschool children in informal settlement areas near Bloemfontein. South Africa Public Health Nutr. 2000;3(3):303-12.

63. Monyeki KD, Cameron N, Getz B. Growth and nutritional status of rural South African children 3-10 years old: The Ellisras growth study. Am J Hum Biol. 2000;12(1):42-9. 
64. Cleaton-Jones $P$, Richardson $B D$, Granath $L$, Fatti $L P$, Sinwell $R$, Walker $A R$, et al. Nutritional status and dental caries in a large sample of 4- and 5-year-old South African children. S Afr Med J. 2000;90(6):631-5.

65. Walsh CM, Dannhauser A, Joubert G. The impact of a nutrition education programme on the anthropometric nutritional status of low-income children in South Africa. Public Health Nutr. 2002;5(1):3-9.

66. Oelofse A, Van Raaij JM, Benadé AJ, Dhansay MA, Tolboom JJ, Hautvast JG. Disadvantaged black and mixed ancestry infants in two urban communities in the Western Cape, South Africa differ in micronutrient status. Public Health Nutr. 2002;5(2):289-94.

67. Chopra M. Risk factors for undernutrition of young children in a rural area of South Africa. Public Health Nutr. 2003;6(7):645-52.

68. Kleynhans IC, Maclntyre U, Albertse EC. Stunting among young black children and the socio-economic and health status of their mothers/ caregivers in poor areas of rural Limpopo and urban Gauteng - the NutriGro Study. South Afr J Clin Nutr. 2006;19(4):163-70.

69. Faber $M$, Benade AJS. Breastfeeding, complementary feeding and nutritional status of 6-12 month old infants in rural kwaZulu-Natal. South Afr J Clin Nutr. 2007;20:1.

70. Smuts CM, Faber M, Schoeman SE, Laubscher JA, Oelofse A, Benadé AJS, et al. Socio-demographic profiles and anthropometric status of 0 - to 71-month-old children and their caregivers in rural districts of the Eastern Cape and KwaZulu-Natal provinces of South Africa. South Afr J Clin Nutr. 2008;21:117-26.

71. Kimani-Murage EW, Kahn K, Pettifor JM, Tollman SM, Dunger DB, Gómez-Olivé XF, et al. The prevalence of stunting, overweight and obesity, and metabolic disease risk in rural South African children. BMC Public Health. 2010;10:158

72. Mamabolo RL, Alberts M, Steyn NP, de Waal HA D-v, Levitt NS. Prevalence and determinants of stunting and overweight in 3-year-old black South African children residing in the Central Region of Limpopo Province, South Africa. Public Health Nutr. 2005;8(5):501-8.

73. Norris SA, Griffiths P, Pettifor JM, Dunger DB, Cameron N. Implications of adopting the WHO 2006 Child Growth Standards: case study from urban South Africa, the Birth to Twenty cohort. Ann Hum Biol. 2009;36(1):21-7.

74. Harrison D. Nutrition. In: Harrison D, editor. South African Health Review 1995. South Africa: Health Systems Trust; 1995. p. 209-21. www.hst.org.za/ publications/south-african-health-review-1995. Accessed 20 December 2013.

75. World Health Organisation, Food and Agriculture Organization. Food Fortification. Protein-Calorie Malnutrition. Geneva: World Health Organization; 1971. Technical report series No 477(WHO)/49(FAO),

76. Seoane N, Latham MC. Nutritional anthropometry in the identification of malnutrition in childhood. J Trop Pediatr Environ Child Health. 1971;17(3):98-104.

77. Waterlow JC. Classification and definition of protein-calorie malnutrition. $\mathrm{Br}$ Med J. 1972;3(5826):566-9.

78. World Health Organisation. UNICEF, Food and Agriculture Organization of the United Nations. Methodology of nutritional surveillance. Geneva: World Health Organization; 1976. Technical report series No 593.

79. Ergo A, Gwatkin DR, Shekar M. Food Nutr Bull. What difference do the new WHO child growth standards make for the prevalence and socioeconomic distribution of undernutrition? 2009;30(1):3-15.

80. Leibbrandt M, Woolard I, de Villiers L. Methodology: Report on National Income Dynamic Study Wave 1. Cape Towna: Southern Africa Labour and Development Research Unit, School of Economics, University of Cape Town; 2009. NIDS Technical Paper No.1.

81. Hales CN, Barker DJP. The thrifty phenotype hypothesis. Br Med Bull. 2001;60:5-20

82. Black RE, Victora CG, Walker SP, Bhutta ZA, Christian P, de Onis M, et al. Maternal and Child Nutrition Study Group. Maternal and child undernutrition and overweight in low-income and middle-income countries. Lancet. 2013;382(9890):427-51.

83. Prentice AM, Ward KA, Goldberg GR, Jarjou LM, Moore SE, Fulford AJ, et al. Critical windows for nutritional interventions against stunting. Am J Clin Nutr. 2013;97(5):911-8.

84. Turok I. Urbanisation and Development in South Africa: Economic Imperatives, Spatial Distortions and Strategic Responses. London: Population and Development Branch, International Institute for Environment and Development; 2012. Urbanization and emerging population issues working paper 8.
85. Kok P, O'Donovan M, Bouare O, van Zyl J. Post-Apartheid Patterns of Internal Migration in South Africa. Cape Town: Human Sciences Research Council (HSRC) publisher; 2003.

86. Collinson M, Tollman S, Kahn K. Migration, settlement change and health in post-apartheid South Africa: Triangulating health and demographic surveillance with national census data. Scand J Public Health Suppl. 2007:69:77-84.

87. Kahn K, Collinson M, Tollman S, Wolff B, Garenne M, Clark S. Health Consequences of Migration: Evidence from South Africa's Rural Northeast (Agincourt). Johannesburg, South Africa: Conference on African Migration in Comparative Perspective; 2003. p. 4-7.

88. Vorster HH, Oosthuizen W, Jerling JC, Veldman FJ, Burger HM, The Nutrition Research Group. The nutritional status of South Africans. A Review of the Literature from 1975-1996. Health Systems Trust: Durban; 1997.

89. Statistics South Africa. http://beta2.statssa.gov.za/. Accessed 20 December 2013

90. Coovadia H, Jewkes R, Barron P, Sanders D, Mclntyre D. The health and health system of South Africa: historical roots of current public health challenges. Lancet. 2009;374(9692):817-34.

91. Wamani H, Astrøm AN, Peterson S, Tumwine JK, Tylleskär T. Boys are more stunted than girls in sub-Saharan Africa: a meta-analysis of 16 demographic and health surveys. BMC Pediatr. 2007;7:17.

92. Veary J. Challenging urban health: towards an improved local government response to migration, informal settlements, and HIV in Johannesburg, South Africa. Global Health Action. 2011;4.

93. Chopra M, Lawn JE, Sanders D, Barron P, Abdool Karim SS, Bradshaw D, et al. Achieving the health Millennium Development Goals for South Africa: challenges and priorities. Lancet. 2009;374(9694):1023-31.

94. Mayosi BM, Lawn JE, van Niekerk A, Bradshaw D, Abdool Karim SS, Coovadia HM. Lancet South Africa team. Health in South Africa: changes and challenges since 2009. Lancet. 2012;380(9858):2029-43.

95. Department of Health. Landscape Analysis on Countries' Readiness to Accelerate Action to Reduce Maternal and Child Under-nutrition: Nationwide Country Assessment in South Africa. Report. Pretoria: Department of Health; 2010. http://www.who.int/nutrition/landscape_analysis/SouthAfrica/en/. Accessed 04 January 2015.

96. Department of Health. Roadmap for Nutrition in South Africa 2013-2017. Pretoria: Department of Health; 2013. https://extranet.who.int/nutrition/gina/ en/node/7994. Accessed 04 January 2015.

97. Monteiro CA, Benicio MH, Conde WL, Konno S, Lovadino AL, Barros AJ, et al. Narrowing socioeconomic inequality in child stunting: the Brazilian experience, 1974-2007. Bull World Health Organ. 2010;88(4):305-11.

\section{Submit your next manuscript to BioMed Central and take full advantage of:}

- Convenient online submission

- Thorough peer review

- No space constraints or color figure charges

- Immediate publication on acceptance

- Inclusion in PubMed, CAS, Scopus and Google Scholar

- Research which is freely available for redistribution 